\title{
openheart Exercise training characteristics in cardiac rehabilitation programmes: a cross-sectional survey of Australian practice
}

\author{
Bridget Abell, ${ }^{1}$ Paul Glasziou, ${ }^{1}$ Tom Briffa, ${ }^{2}$ Tammy Hoffmann ${ }^{1}$
}

To cite: Abell B, Glasziou P, Briffa T, et al. Exercise training characteristics in cardiac rehabilitation programmes: a crosssectional survey of Australian practice. Open Heart 2016;3: e000374. doi:10.1136/ openhrt-2015-000374

- Additional material is available. To view please visit the journal (http://dx.doi.org/ 10.1136/openhrt-2015000374)

Received 26 November 2015 Revised 23 December 2015 Accepted 2 February 2016

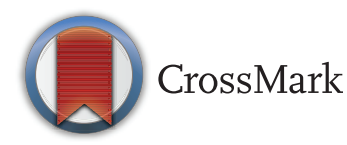

\footnotetext{
${ }^{1}$ Faculty of Health Sciences and Medicine, Centre for Research in Evidence-Based Practice, Bond University, Gold Coast, Queensland, Australia

${ }^{2}$ School of Population Health, The University of Western Australia, Perth, Western Australia, Australia
}

Correspondence to Bridget Abell; babell@bond.edu.au

\section{ABSTRACT}

Introduction: Exercise training is a core component of cardiac rehabilitation (CR), however, little information exists regarding the specific exercise interventions currently provided for coronary heart disease in Australian practice. We aimed to analyse the current status of exercise-based CR services across Australia. Design: Cross-sectional survey.

Methods: Australian sites offering exercise-based CR were identified from publically available directories. All sites were invited by email to participate in an online Survey Monkey questionnaire between October 2014 and March 2015, with reminders via email and phone follow-up. Questions investigated the demographics and format of individual programmes, as well as specific exercise training characteristics.

Results: 297 eligible programmes were identified, with an $82 \%$ response rate. Most sites (82\%) were based at hospital or outpatient centres, with home $(15 \%)$, community $(18 \%)$ or gym-based options $(5 \%)$ less common. While CR was most often offered in a comprehensive format ( $72 \%$ of sites), the level of exercise intervention varied greatly among programmes. Most frequently, exercise was prescribed 1-2 times per week for 60 min over 7 weeks. Almost one-quarter (24\%) had a sole practitioner supervising exercise, although the majority used a nurse/ physiotherapist combination. Low to moderate exercise intensities were used in $60 \%$ of programmes, however, higher intensity prescriptions were not uncommon. Few sites $(<6 \%)$ made use of technology, such as mobile phones or the internet, to deliver or support exercise training.

Conclusions: While advances have been made towards providing flexible and accessible exercisebased CR, much of Australia's service remains within traditional models of care. A continuing focus on service improvement and evidence-based care should, therefore, be considered a core aim of those providing exercise for $\mathrm{CR}$ in order to improve health service delivery and optimise outcomes for patients.

\section{INTRODUCTION}

Cardiac rehabilitation (CR) aims to support people with coronary heart disease to return

\section{KEY QUESTIONS}

What is already known about this subject?

- Exercise training is recognised as a core component of cardiac rehabilitation (CR) programmes worldwide, yet the provision of this intervention in clinical practice has been shown to vary markedly. Previous studies have also highlighted inconsistencies in exercise training delivered in clinical practice with that observed in randomised controlled trials.

What does this study add?

- This study contributes an Australian perspective to research examining the provision of exercise training during CR. Considerable variability in exercise training characteristics was observed across Australian programmes, yet individual programmes themselves offered patients with few options for exercise. Most of the exercise training provided within Australian CR programmes remains within traditional hospital, group-based models.

How might this impact on clinical practice?

- This study has provided a benchmark for current Australian practice, and highlighted several areas for service improvement. Most importantly, it reiterates the need for a continued effort in service redesign to provide accessible, flexible and effective models of care.

to an active and fulfilling lifestyle, and facilitate secondary prevention of the disease. ${ }^{12}$ The process of rehabilitation begins as an inpatient with early mobilisation, education and optimisation of medical therapy (phase 1), however, it is phase 2 rehabilitation, which begins on hospital discharge, which is considered core to the intervention process. This phase of CR generally involves exercise therapy coupled with disease education, risk factor management, and psychosocial care, and provides the support and encouragement needed for patients to adopt long-term self-management behaviours. 
Evidence supports the benefits of structured CR in preventing new cardiac events, as well as for improving patients' cardiovascular risk profile, physical functioning and quality of life. ${ }^{3-6}$ Consequently, participation in CR programmes is seen as an integral part of secondary prevention, and is included in clinical guidelines for coronary heart disease management globally. ${ }^{2}$-9

Exercise training is a core component of cardiac rehabilitation, ${ }^{10-12}$ yet there is considerable ambiguity and variation in interventions of this type used within the research. A recent overview of Cochrane systematic reviews ${ }^{5}$ highlighted the substantial variability in interventions contained within trials of exercise-based CR, CR for heart failure, and home versus centre-based CR. Consequently, studies examining the clinical provision of exercise-based CR in Europe ${ }^{13} 14$ and the $\mathrm{UK}^{15-17}$ have found marked variation in the type, duration, frequency, intensity and total training volume of exercise offered. Importantly however, these studies also highlighted inconsistencies in the exercise interventions delivered in many of these programmes compared to those recommended in the literature. Patients attending these programmes may, therefore, be receiving less than optimal exercise-based CR, and hence, suboptimal benefit from this intervention.

Recently, the Australian Cardiovascular Health and Rehabilitation Association published a guidance document highlighting the core components of secondary prevention and CR which should be contained within effective services. ${ }^{10}$ One of the core components is that structured exercise training should be provided to all patients unless contraindicated. However, beyond the recommendations to measure baseline functional capacity, increase physical activity levels to meet guidelines, ${ }^{18}$ and refer to exercise specialists, there is no clear guidance about the exercise prescription in Australian clinical practice. An earlier national framework document ${ }^{19}$ also suggested that the exercise prescription could be varied according to the available resources and patient needs. Consequently, it is possible that the nature of exercise intervention provided in Australian CR programmes may vary considerably.

Little information currently exists regarding the specific exercise interventions that are provided in Australian practice. A 2009 audit $^{20}$ used CR service directories to summarise the general characteristics of Australian programmes in terms of model of care, setting and duration. However, it did not explore programme components in any more detail, or contact providers directly to validate the directory information. More detailed information about individual programmes is vital to benchmark and inform quality improvement of services, as well as identify any evidence-practice gaps. This study, therefore, aimed to conduct a nationwide survey of the current status of exercise-based CR services in Australia, with particular focus on the individual elements of the exercise intervention.
METHODS

\section{Design}

A cross-sectional survey.

\section{Participants}

CR sites and coordinators were identified from publically available service directories hosted on the Australian Cardiovascular Health and Rehabilitation Association (ACRA) website. $^{21}$ These directories, maintained by the National Heart Foundation and state CR branches, are the main source of information for referral to $\mathrm{CR}$ nationwide, containing contact details and brief descriptions of services. A list of potentially eligible survey participants was generated, comprising all sites which reported providing phase 2 exercise-based CR (in any form) for referred patients. Sites listed in the directory without a description of services were also included to ensure that no eligible programmes were missed. Sites which provided education only, in-patient (phase 1), or stand-alone heart-failure rehabilitation, were excluded, as the content and structure of these programmes often differs markedly.

\section{Procedure}

The survey was conducted between October 2014 and March 2015. Initially, an email was sent to all potentially eligible contacts inviting them to participate in an online questionnaire via a link to the Survey Monkey platform. Participants could also complete the survey over the phone if preferred. If the recipient was unable to complete the survey personally, we asked them to forward the invitation to someone who could. When emails bounced, or we were notified that the invitation was delivered to the wrong recipient, we contacted the site by phone to obtain new coordinator details. Non-responsive sites, or those with incomplete surveys, were sent up to two reminder emails, each 1 month apart. If no response was received after three emails, we telephoned sites directly to clarify contact details and send new invitations if required.

\section{Survey}

The survey consisted of three main sections: (1) programme demographics, (2) overall programme style and content and (3) the individual components of exercise training. For the third section, the items from the Template for Intervention Description and Replication guide $^{22}$ were used to capture the essential elements of the exercise intervention offered within each programme. The survey consisted of 46 multiple choice and short-answer questions. Where sites offered more than one version of CR programme (eg, home and centre), the survey directed them to an additional section (that repeated up to 25 earlier questions) so that information was captured about each programme version.

Initially, the survey was piloted with a convenience sample of coordinators at eight sites. The final version contained minor adjustments based on this feedback 
(see online supplementary appendix 1). To optimise response rates, official endorsement of the survey was obtained from ACRA and noted in the covering email.

\section{Data analysis}

All responses collected via Survey Monkey were inspected, downloaded into Excel, coded and analysed using descriptive statistics (means, frequency, percentage). Surveys were classified as complete if respondents provided answers to $\geq 80 \%$ of questions. ${ }^{23}$ Surveys with $50-79 \%$ of questions answered were categorised as mostly complete, and those with responses to $<50 \%$ as incomplete. All returned surveys were included in analysis, regardless of the amount of missing data. Consequently, the number of total responses for each individual question varied due to missing data, refusal/ inability to answer a question, and the use of skip logic.

Established tables and formulas ${ }^{24} 25$ were used to assess comparability of exercise intensities reported in varying formats (eg, Borg scale, ${ }^{26}$ modified Borg scale, ${ }^{26}$ $\%$ maximal heart rate/MHR), as well as classify exercise as low, moderate or high intensity. The total number of exercise sessions offered at each site was calculated by multiplying the duration of the programme by the reported frequency of attendance.

\section{RESULTS}

Invitations were sent to 398 unique and potentially eligible CR contacts. Some of these coordinators were responsible for the management of programmes across multiple sites. As displayed in figure 1, a total of 297 sites were eligible for participation in the survey, with an additional 8 non-responding sites whose eligibility was uncertain (305 in total). Of the sites, 251 (82\%) responded: $225(74 \%)$ provided complete surveys, 19
$(6 \%)$ provided mostly complete surveys, and $7(2 \%)$ completed $<50 \%$ of questions. In total, 93 (23\%) of the contacted sites were ineligible (see online supplementary appendix 2 for exclusion reasons).

Brief programme descriptions were available in state directories for 46 of the non-responding sites (see online supplementary appendix 3 ). We used this information to examine the programme characteristics of non-responding sites compared to those included in the survey. Non-responding sites appeared similar to included programmes.

\section{Programme Demographics}

Australian CR programmes were distributed across metropolitan, regional and rural areas, with the majority $(62 \%)$ in operation for $>10$ years (table 1$)$. They most frequently enrolled 101-500 patients per year, however, programmes with small enrolments ( $<50$ patients) constituted almost one-third of the nation's CR service. All programmes accepted referrals for patients postmyocardial infarction, after cardiac surgery (bypass graft, valve) and postcoronary intervention (angioplasty, stent). A substantial proportion $(\mathrm{n}=203,85 \%)$ also provided primary prevention for patients at high risk of coronary heart disease. The public health system $(68 \%)$ or private insurance (13\%) funded attendance at most sites, however, those in commercial gyms, or based in Victoria, asked for an additional contribution from patients for each session (usually $\$ A 7-8$ ).

\section{Overall style and content}

CR services were most frequently delivered in a comprehensive format covering all core components (table 2). These components were offered in an individualised, modular fashion at $23 \%$ of sites, with only a small

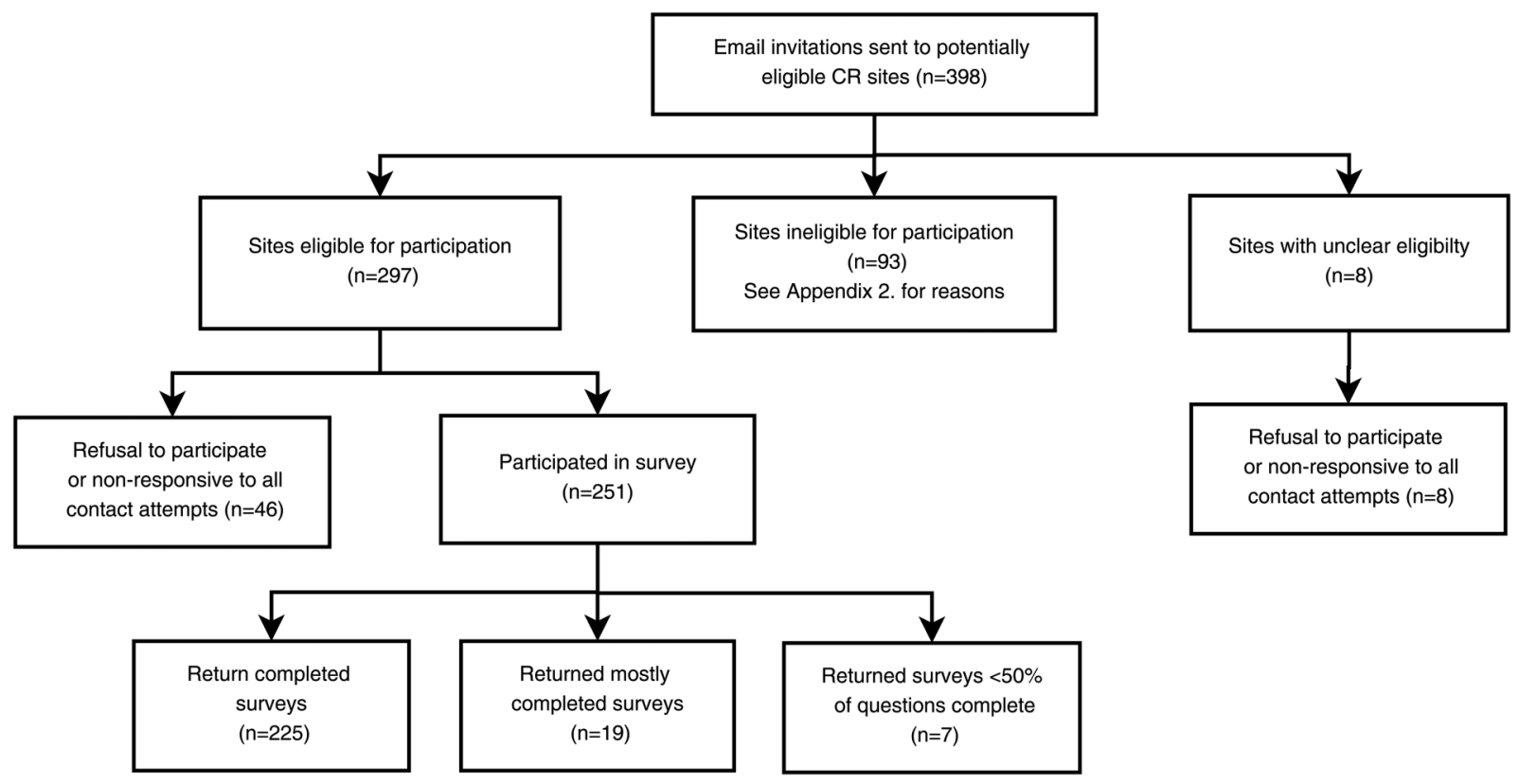

Figure 1 Flow chart of survey participants and responses. 
Table 1 Demographics of Australian sites providing exercise-based cardiac rehabilitation

\begin{tabular}{|c|c|c|}
\hline \multirow{2}{*}{$\frac{\text { Demographic }}{\text { Site location }(n=251)}$} & \multicolumn{2}{|c|}{$\begin{array}{l}\text { Number of } \\
\text { sites (\%) }\end{array}$} \\
\hline & & \\
\hline Metropolitan & 89 & (35.5) \\
\hline Regional & 62 & $(24.7)$ \\
\hline Rural & 100 & (39.8) \\
\hline \multicolumn{3}{|l|}{ Total time operating $(n=239)$ (years) } \\
\hline$<1$ & 4 & $(1.7)$ \\
\hline $1-5$ & 38 & (15.9) \\
\hline$>5-10$ & 48 & $(20.1)$ \\
\hline$>10$ & 149 & (62.3) \\
\hline \multicolumn{3}{|l|}{ Yearly number of patient enrolments $(n=234)$} \\
\hline$<50$ & 67 & $(28.6)$ \\
\hline $50-100$ & 66 & $(28.2)$ \\
\hline $101-500$ & 90 & (38.5) \\
\hline$>500$ & 11 & $(4.7)$ \\
\hline \multicolumn{3}{|l|}{ Participation costs $(n=235)$} \\
\hline No cost to patient (public funding) & 160 & $(68.1)$ \\
\hline $\begin{array}{l}\text { No cost to patient (private insurance } \\
\text { coverage) }\end{array}$ & 30 & (12.8) \\
\hline $\begin{array}{l}\text { No cost to patient (both public and private } \\
\text { funding) }\end{array}$ & 13 & (5.5) \\
\hline $\begin{array}{l}\text { Patient pays some or all of cost (eg, } \\
\text { nominal session fee) }\end{array}$ & 32 & (13.6) \\
\hline
\end{tabular}

number providing exercise training alone. The number of health professionals in each CR team ranged from 1 to 12 , with a mean of $6 \quad(\mathrm{SD}=2)$ involved in some element of programme delivery. Nurses were employed in $88 \%$ of all programmes, with most also including a dietitian and physiotherapist (table 2). Programmes were most commonly offered in hospital outpatient settings $(81 \%)$, with fewer providing options for patients in community-based locations, at home, or in a commercial gym. Only $44(18 \%)$ sites offered participants the choice of more than one location for exercise, and $164(65 \%)$ only offered hospital-based programmes. Almost all sites provided CR in a group-based setting (240/245; 98\%), however, $17 \%$ offered the additional choice of individual-based exercise and/or education sessions. CR, and particularly exercise training, was delivered using largely traditional means. Few sites made use of technology or novel delivery methods (table 2), and generally only to provide education rather than deliver or support exercise training. Supplemental materials used to aid exercise training consisted of exercise logs (166/234; $71 \%$ of sites), heart rate monitors $(50 \%)$, pedometers (15\%; mainly for home programmes) and on-site telemetry when required $(12 \%)$. No regular method of monitoring exercise training was reported by $15 \%$ of sites.

\section{Exercise training components}

Functional capacity assessment

At almost all sites (91\%; 207/227), an assessment of functional capacity was performed preprogramme, however, fewer sites performed repeat testing postprogramme $(62 \%)$, or at $3(14 \%), 6(11 \%)$ or 12 month follow-up $(7 \%)$. The most frequently reported reasons for measuring functional capacity were tracking progress and improvement $(\mathrm{n}=183,83 \%)$, determining exercise intensity $(\mathrm{n}=146,66 \%)$, symptom monitoring $(\mathrm{n}=96$, $44 \%)$, and risk stratification $(\mathrm{n}=92,42 \%)$. The $6 \mathrm{~min}$ walk test was the most frequently used method to assess functional capacity, with $86 \%(180 / 210)$ of sites reporting it as their primary test. Only six sites (3\%) regularly used traditional exercise treadmill testing to assess patients, with 13 using some other form of heart ratebased submaximal test. Other tests less frequently used in functional assessment included $\mathrm{VO}_{2}$ testing, the $10 \mathrm{~m}$ Incremental Shuttle Walk Test, and the Timed Up and Go Test.

\section{Exercise supervision}

A mean of 2 (range 1-4) staff were directly involved in the supervision of exercise training across sites. This was most commonly a nurse $(87 \% ; n=193)$ or physiotherapist $(66 \% ; n=148)$, however, allied health assistants and exercise physiologists filled these roles in approximately one-third of cases. Fifty-three sites (22\%) reported having a sole staff member supervising exercise, usually a nurse, exercise physiologist or physiotherapist. Several respondents commented that the level of nursing staff knowledge and ability with exercise for cardiac conditions varied widely.

\section{Training modality}

Aerobic exercise training was used by all programmes, with $226(96 \%$; $=235)$ also including resistance training or body-weight exercises in their regimes. In most cases $(72 \%)$, resistance-based exercises were incorporated with aerobic modalities in the form of circuit training. Thirteen different modalities of aerobic training were reported across the programmes (see online Supplementary appendix 4), with the most commonly used being cycling (216/235; 92\%) and walking (82\%; $\mathrm{n}=193$ ). In the majority of programmes, the choice of exercise modality was a joint decision between staff and participant, however, in $27 \%$ it was chosen solely by the programme staff. Additionally, 29 (13\%) programmes used Tai Chi, 9 (4\%) included balance training, and 4 (2\%) incorporated yoga exercises.

\section{Programme duration}

Programme duration varied widely, ranging from 3 weeks to 'ongoing' (table 3). Programme lengths of 6 weeks $(n=80 ; 33 \%)$ or 8 weeks $(n=63 ; 26 \%)$ were the most commonly reported. Of all programmes, $78 \%$ lasted between 6 and 8 weeks, and $<5 \%$ lasted longer than 12 weeks.

\section{Frequency of sessions}

The frequency of exercise sessions prescribed to CR participants varied from once per week to daily (table 3 ). 
Table 2 Overall style and general characteristics of Australian exercise-based cardiac rehabilitation services

\begin{tabular}{|c|c|c|}
\hline \multirow{2}{*}{$\begin{array}{l}\text { Characteristic } \\
\text { Type of programme }(n=251)\end{array}$} & \multicolumn{2}{|c|}{ Number of programmes (\%) } \\
\hline & & \\
\hline Comprehensive CR services offered for all patients & 180 & (72.3) \\
\hline Modular (CR services offered vary by patient) & 57 & (22.9) \\
\hline Exercise only & 9 & (3.6) \\
\hline Non-CR specific chronic disease exercise classes & 5 & (2.0) \\
\hline \multicolumn{3}{|l|}{ Content of programme $(n=251)$} \\
\hline Exercise training & 251 & (100) \\
\hline Health education (eg, risk factors, chest pain management) & 245 & (97.6) \\
\hline Dietary advice or counselling & 222 & (88.4) \\
\hline Psychological advice or counselling & 217 & (86.5) \\
\hline Medication education & 215 & (85.7) \\
\hline Relaxation training & 189 & (75.3) \\
\hline Smoking cessation & 166 & (66.1) \\
\hline \multicolumn{3}{|l|}{ Programme setting for exercise $(n=251)$} \\
\hline Hospital outpatient centre & 204 & (81.3) \\
\hline Community (eg, hall, park, local medical practice) & 46 & (18.3) \\
\hline Home & 37 & (14.7) \\
\hline Commercial gym & 12 & (4.8) \\
\hline \multicolumn{3}{|l|}{ Programme staff $(n=241)$} \\
\hline Nurse & 213 & (88.4) \\
\hline Dietitian/nutritionist & 198 & (82.2) \\
\hline Physiotherapist & 185 & (76.8) \\
\hline Pharmacist & 167 & (69.3) \\
\hline Occupational therapist & 146 & (60.6) \\
\hline Social worker & 126 & (52.3) \\
\hline Allied health assistant/physiotherapy assistant & 92 & (38.2) \\
\hline Exercise physiologist & 79 & (32.8) \\
\hline Psychologist & 69 & (28.7) \\
\hline Doctor (other than cardiologist) & 46 & (19.1) \\
\hline Cardiologist & 34 & (14.1) \\
\hline Cultural health worker & 28 & (11.6) \\
\hline Other* & 32 & (13.3) \\
\hline \multicolumn{3}{|l|}{ Technology used to deliver programme, or support patients $(n=228)$} \\
\hline Telephone (motivation and support) & 62 & (27.2) \\
\hline Videoconferencing (off-site education) & 13 & (5.7) \\
\hline Internet (telehealth, off-site education) & 7 & (3.0) \\
\hline Mobile phone (SMS reminders, smart phone applications) & 5 & (2.2) \\
\hline
\end{tabular}

One home-based programme prescribed exercise 5-7 days/week; one centre-based programme offered sessions four times per week; and 16 other sites offered thrice-weekly exercise sessions. The remainder offered exercise less than three times per week, with $52 \%$ $(\mathrm{n}=142)$ reporting weekly sessions, and $40 \% \quad(\mathrm{n}=110)$ twice weekly exercise sessions. Only $10 \%(\mathrm{n}=24)$ offered a choice in frequency of attendance for exercise sessions.

Table 3 Characteristics of individual components of exercise training in Australian cardiac rehabilitation services

\begin{tabular}{|c|c|c|c|c|c|}
\hline \multirow{2}{*}{$\begin{array}{l}\text { Characteristic } \\
\text { Duration of programme (weeks) }\end{array}$} & \multicolumn{2}{|c|}{ Mean (SD) } & \multirow{2}{*}{$\begin{array}{l}\text { Range } \\
3-14^{*}\end{array}$} & \multirow{2}{*}{$\begin{array}{l}\text { Responding } \\
\text { sites, n } \\
246\end{array}$} & \multirow{2}{*}{$\begin{array}{l}\text { Variations } \\
\text { reported, } \\
\text { n }\end{array}$} \\
\hline & 7.0 & $(1.7)$ & & & \\
\hline Frequency of exercise sessions (days per week) & 1.6 & $(0.8)$ & $1-7$ & 244 & 257 \\
\hline Total number of exercise sessions in programme & 11.3 & (5.5) & $3-42$ & 244 & 368 \\
\hline Exercise session duration (min) & 55.5 & $(13.4)$ & $15-120$ & 235 & 235 \\
\hline Exercise intensity (all converted to Borg scale) & $11-13$ & & $10-17$ & 194 & 194 \\
\hline
\end{tabular}



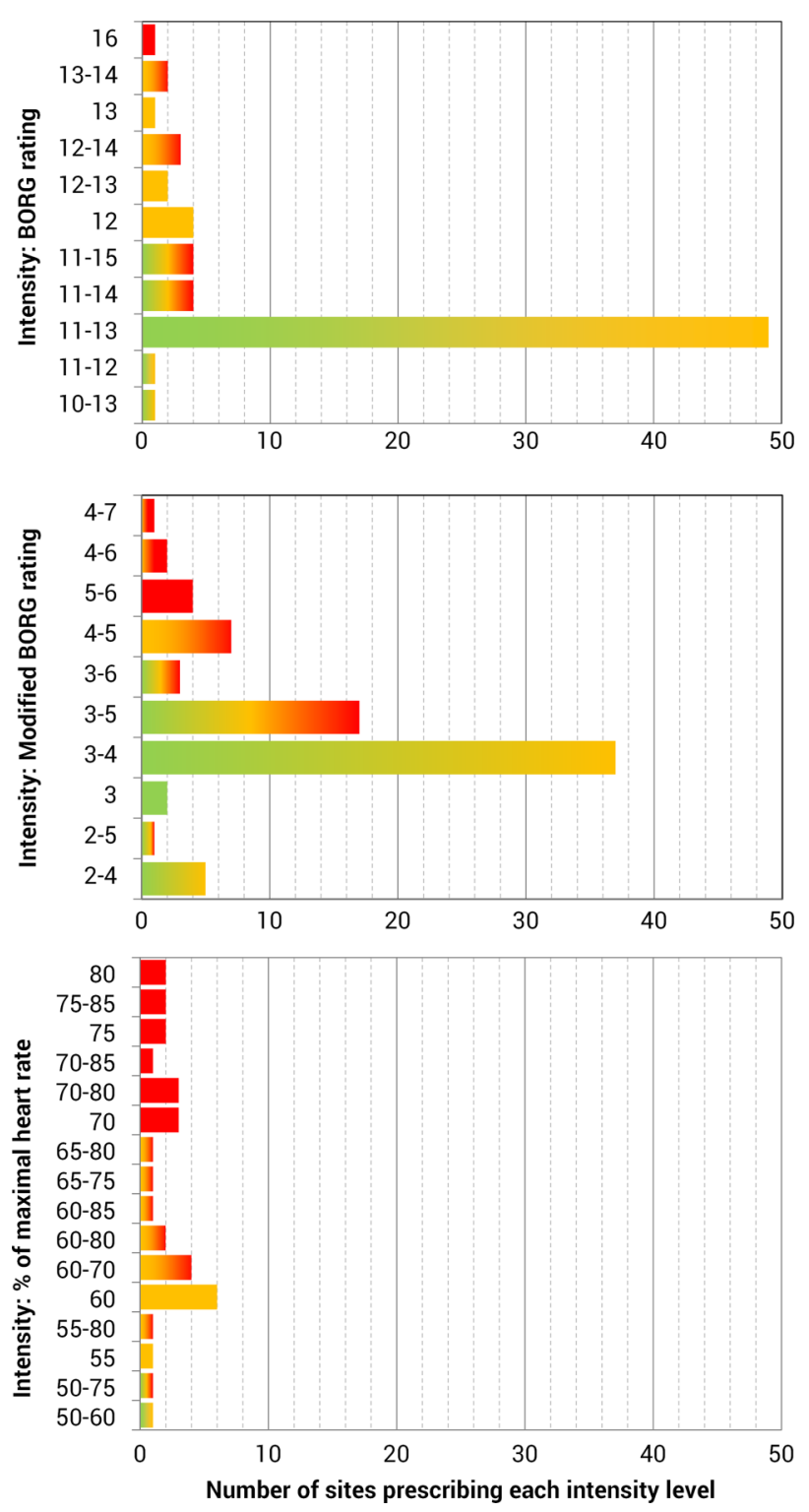

Figure 2 Frequency counts of exercise intensities routinely prescribed in programmes $(n=194)$ grouped by method/scale. The colour of the bar represents the corresponding level of intensity (green= low; yellow= moderate; red=high, eg, green and yellow bars represent low to moderate intensity programmes). See online supplementary appendix 5 for the same results with intensity levels based on new classifications by the American College of Sports Medicine.

\section{Total number of exercise sessions}

Overall, the total number of exercise sessions offered by programmes ranged from 3 (fast-track evening programme) to 42 (3 times per week for 14 weeks), with a mean of $11 \quad(\mathrm{SD}=6)$ (table 3). Less than half $(46 \%$; $\mathrm{n}=109$ ) of all individual sites, however, offered programmes with options for 12 or more sessions.

Regardless of the number of exercise sessions formally offered as part of each programme, all sites reported encouraging participants to undertake extra physical activity at home for the duration of the programme. This was either in the form of advice such as 'walk 3-5 times per week' or, participants were given a specific exercise programme. Only one-third of sites, however $(72 / 220 ; 33 \%)$, reported formally monitoring or encouraging this additional training, with checks of training diaries, verbal inquiries or pedometer use.

\section{Duration of sessions}

The time spent exercising at each session also varied widely: from 15-30 min at one centre up to $120 \mathrm{~min}$ at two others. Exercise sessions lasting $60 \mathrm{~min}$ were the most frequently reported $(127 / 235 ; 54 \%)$. Sessions lasting $30 \mathrm{~min}$ or less, or more than $60 \mathrm{~min}$, occurred at only $13 \%$ of sites.

\section{Exercise intensity and progression}

Borg's Rating of Perceived Exertion (RPE) was the most frequently reported method of prescribing exercise intensity, with $46 \%(102 / 222)$ of programmes using the modified $0-10$ category ratio scale, and $34 \%$ (75/222) using the original $6-20$ scale. Few sites prescribed exercise intensity based on a percentage of predicted MHR $(n=24 ; 11 \%)$, heart rate reserve (HRR, $n=5 ; 2 \%)$, or the heart rate obtained from exercise testing $(\mathrm{n}=14 ; 6 \%)$.

In absolute terms, 11-13 on the Borg scale was the most frequently prescribed intensity level (49/194; $25 \%$ of all responding sites), followed by $3-4$ on the modified Borg scale $(37 / 194 ; 19 \%)$, and then $3-5$ on the modified Borg scale (17/194; 9\%) (figure 2). Additionally, 8 sites reported intensity targets based on the individual person, 1 simply aimed for heart rates $<120 \mathrm{bpm}$, and it was not set by 2 sites. When converting all reported intensities to the same scale, a level of 11-13 Borg (corresponding to 3-4 mBorg and 54-69\% MHR) was still the most frequently used training intensity, with $44 \%$ of sites prescribing exercise at this level. Over half of all sites $(60 \% ; n=110)$ delivered exercise training classified as low to moderate intensity, with $13 \%$ prescribing moderate to high-intensity exercise, and $10 \%$ (19 sites) reportedly prescribing only high-intensity exercise $(\geq 14$ Borg/70\% MHR).

The importance of exercise progression and tailoring was recognised by most respondents, with 97\% (204/211) reporting staff progressed participants individually through increasing levels of exercise based on observation of symptoms, physiological response to training and RPE.

\section{Exercise adherence and maintenance}

Respondents were asked to report on adherence to the exercise component of their programmes based either on attendance records, exercise logs or, if not formally measured $(<10 \%$ of respondents), a best estimate of adherence. Just over half $(59 \%$; $130 / 222)$ of all programmes provided exercise adherence figures that were classified as high (defined as $>75 \%$ of all participants who began the exercise programme completed it, or, on average, participants attended more than $75 \%$ of all offered exercise sessions). A further $29 \%$ reported moderate levels of adherence (50-75\% exercise programme 
completion/session attendance), and $13 \%$ described exercise adherence of $<50 \%$. The median response reported across all programmes was exercise adherence of $70-80 \%$.

While only $32 \%$ of programmes $(70 / 217)$ offered ongoing maintenance exercise classes for former participants at the same location as their phase 2 programmes, the remainder reported providing home exercise programmes or referring to other community services.

\section{DISCUSSION}

This nationwide survey formally documents the characteristics and type of exercise training delivered in Australian CR practice. While exercise training was consistently identified as a core component of CR delivery, the characteristics of this training varied widely. Despite this national variation in exercise interventions, most individual programmes offered participants little choice, and most of Australia's CR service is provided within traditional models of care.

This study contributes an Australian perspective to the body of research which has examined the provision of exercise training during CR in other nations. ${ }^{14-17}$ 27-33 Many of these earlier studies, however, are over a decade old, and the nature of CR has evolved over this time. Nevertheless, the characteristics of exercise training in Australian CR programmes identified in this study were similar to those observed in England, ${ }^{16}{ }^{28}$ Wales $^{16}$ and Ireland ${ }^{17}$ in terms of duration, frequency, number of sessions, session time and supervision team. While the proportion of hospital-based programmes was also similar across these nations, Australian services made less use of community and commercial settings for exercise. Development of Australian CR services to make better use of these locations, could potentially provide a resource-saving and more accessible exercise option, particularly for patients at lower risk of a new vascular event.

By contrast with our findings, surveys conducted in Europe, ${ }^{14}{ }^{30}$ Canada, $^{31}$ the USA $^{32}{ }^{33}$ and South America $^{29}$ reported greater volumes of exercise training, with both longer duration programmes and more frequent sessions. European and American programmes contained, on average, twice as many exercise sessions as Australian programmes, which is possibly explained by differences in healthcare systems and funding models. ${ }^{32} 34$ Additionally, recommendations in the Australian CR framework require a minimum of 6-8 exercise sessions, ${ }^{19} 34$ while other international guidance recommends at least $12-36 .{ }^{35-37}$ The reason for such a wide variation in international guideline recommendation is unclear, and should be explored in further research.

\section{Implications for practice}

Concerns have been raised that a continuing emphasis on traditional models of CR presents substantial barriers for physician acceptance, patient uptake, programme accessibility, resourcing and funding. ${ }^{2} 38$ Calls for a 're-engineering' of the CR model have occurred internationally ${ }^{38}{ }^{40}$ and at a local level. ${ }^{41}$ Within Australia, the need for a more flexible, accessible and integrated approach was highlighted in 2009, when a brief audit of CR services $^{20}$ found the majority provided outpatient, time-limited programmes with little flexibility. One aim of our survey was to expand on this audit by providing a more detailed snapshot of CR practice, as well as exploring if progress had been made towards delivering more flexible models of care.

It appears that Australian programmes are now more flexible in their overall approach to CR, with many providing the core components in a modular fashion. However, our findings indicate that for exercise training, flexibility of service delivery is yet to reach a tipping point. While the nationwide variation in exercise offered is congruent with the recent recommendation to offer CR using an individualised, 'menu-based approach', ${ }^{11}$ it must be reiterated that the individual programmes themselves provide limited choices for patients. For the most part, exercise interventions are still duration limited and group based, with the proportion of programmes providing flexible exercise settings generally unchanged. The increase in home-based programmes in the past 6 years (from $4 \%^{20}$ to $15 \%$ ) is encouraging, and congruent with the growing body of research demonstrating greater access and comparable effectiveness of home-based models to traditional CR formats. ${ }^{42}$ However, this shift may have also evolved out of necessity, as the survey identified 24 services which had ceased operations, and many more which had reduced operating hours and staff due to funding cuts. As the demand on staffing and resources is typically less for home-based programmes, they may have become the default means of providing care in settings with limited funding.

This decline in programme funding may also be contributing to the failure to redesign and offer more flexible CR models. Without adequate support and seed funding, delivering a true menu-based approach for all patients in practice is often unfeasible. ${ }^{43} 44$ The type of programme offered is less likely to be influenced by patient preferences and, instead, constrained by what can be provided within available funding and service frameworks. This problem was raised by CR providers in our survey who reported service provision was hampered by time, support and resourcing constraints. This finding is not unique to Australia, with surveys of clinical practice in England ${ }^{15}{ }^{43}$ also highlighting substantial underfunding; leading to decreased staffing, session availability, facilities and personnel training.

CR practitioners are faced with the difficult challenge of reconfiguring services in a climate of competitive healthcare funding. Fortunately, successful local initiatives which attempt service redesign with minimal impact on staffing and resources ${ }^{45}$ have already begun. Additionally, uptake of evidence-based technologies 
(such as text messaging, ${ }^{46}$ or smartphone $\mathrm{CR}^{47}$ ) recently trialled locally, needs to be encouraged and coupled with an increased use of existing infrastructure to deliver all or part of CR programmes (such as partnerships with community centres, gyms and commercial entities, or referral to exercise physiologists). In doing so, it may be possible to provide increased flexibility for patients without an additional resource drain on services. This may be particularly beneficial for rural or small programmes which comprise a significant proportion of Australian CR services, and are often the first at risk of closure.

While flexible models are strongly advocated, this approach also comes with the important caveat that providers ensure that all components delivered, including exercise training, meet the minimum level required to achieve benefit. In the deconditioned populations most often attending CR, benefits may occur with relatively small amounts of training, however, it is still concerning that a large proportion of Australian programmes are only able to offer formal exercise sessions once per week. While evidence suggests that 'hybrid' programmes containing one formal weekly group session with two additional and equivalent home-based sessions, may be just as effective as three hospital-based sessions, ${ }^{35}$ it is not clear if Australian programmes are providing equivalent home-based sessions. In our study, only one-third reported formally monitoring or encouraging exercise outside of prescribed classes. To reap the full potential of exercise training, programmes should take an active role in providing participants with a detailed and individualised exercise prescription for use outside of formal sessions (based on risk and functional status), and routinely monitor and encourage its use. While Australian programmes currently meet the majority of exercise recommendations prescribed in their own nominal guidelines, it is also pertinent to examine further whether the 'real-life provision' of exercise training in Australian CR, like that in the UK, fails to meet the levels observed in RCTs and recommended in international clinical guidelines. ${ }^{48} 49$

\section{Strengths and limitations}

A major strength of this study is its high response rate with $86 \%$ of all known CR sites contributing to the survey. Hence, this study provides a representative and comprehensive reflection of current exercise provision in Australia. While every effort was made to locate all eligible CR services, it is possible that not all providers are listed in the ACRA directories. Given the directories are considered the main resource for referral nationwide, there would likely be only a handful of sites receiving limited numbers of referrals if not listed. Additionally, our survey only captured exercise interventions which were delivered by programmes in-house, however, approximately $10 \%$ of sites referred to external providers, such as exercise physiologists, who may have provided a more individualised, increased level of exercise training. A review of exercise training delivered by external providers may be warranted in the future if the number of patients referred to this type of service increases.

\section{CONCLUSIONS}

Our survey has provided a detailed and comprehensive snapshot of the current delivery of exercise-based CR within Australia, and also identified several potential opportunities for future service improvement. While advances have been made towards increased flexibility and accessibility of CR services, there are still significant benefits to be gained from improving the provision of exercise training. A continued focus on this challenge will not only benefit Australian patients participating in CR, but may also aid in closing evidence-practice gaps and contribute important knowledge towards improvements in CR globally.

Contributors BA contributed to the conception of idea; study planning; design of survey; collection, analysis and interpretation of the data; and writing of the manuscript. PG contributed to the study planning, design of survey and critical revision of the manuscript. TB contributed in the design and processes of the survey and critical revision of the manuscript. TH contributed to the study planning, design of survey and critical revision of the manuscript.

Funding BA is supported by an Australian Postgraduate Award funded by the Australian Federal Government. PG is supported by a National Health and Medical Research Council Research Fellowship (GNT1080042). TH is supported by a National Health and Medical Research Council of Australia/ Primary Health Care Research Evaluation and Development Career Development Fellowship (1033038).

Competing interests None declared.

Ethics approval Obtained from Bond University's Human Research Ethics Committee (approval number R01862), and participants provided informed consent before participating.

Provenance and peer review Not commissioned; externally peer reviewed.

Data sharing statement Requests for access to raw data (also collated at regional/state level) can be made by contacting the corresponding author.

Open Access This is an Open Access article distributed in accordance with the Creative Commons Attribution Non Commercial (CC BY-NC 4.0) license, which permits others to distribute, remix, adapt, build upon this work noncommercially, and license their derivative works on different terms, provided the original work is properly cited and the use is non-commercial. See: http:// creativecommons.org/licenses/by-nc/4.0/

\section{REFERENCES}

1. World Health Organization. Needs and action priorities in cardiac rehabilitation and secondary prevention in patients with $C H D$. Geneva: WHO, 1993.

2. National Heart Foundation of Australia. Secondary prevention of cardiovascular disease. 2010. https://heartfoundation.org.au/images/ uploads/publications/Secondary-Prevention-of-cardiovasculardisease.pdf

3. Oldridge N. Exercise-based cardiac rehabilitation in patients with coronary heart disease: meta-analysis outcomes revisited. Future Cardiol 2012;8:729-51.

4. Heran BS, Chen JM, Ebrahim S, et al. Exercise-based cardiac rehabilitation for coronary heart disease. Cochrane database Syst Rev 2011;(7):CD001800.

5. Anderson L, Taylor RS. Cardiac rehabilitation for people with heart disease: an overview of Cochrane systematic reviews. Cochrane Database Syst Rev 2014;(12):CD011273. 
6. Müller-Riemenschneider F, Meinhard C, Damm K, et al. Effectiveness of nonpharmacological secondary prevention of coronary heart disease. Eur J Cardiovasc Prev Rehabil 2010;17:688-700.

7. Montalescot G, Sechtem U, Achenbach S, et al. 2013 ESC guidelines on the management of stable coronary artery disease: the Task Force on the management of stable coronary artery disease of the European Society of Cardiology. Eur Heart J 2013;34:2949-3003.

8. Smith SC, Benjamin EJ, Bonow RO, et al. AHA/ACCF secondary prevention and risk reduction therapy for patients with coronary and other atherosclerotic vascular disease: 2011 update: a guideline from the American Heart Association and American College of Cardiology Foundation. Circulation 2011;124:2458-73.

9. National Clinical Guideline Centre. MI-secondary prevention: secondary prevention in primary and secondary care for patients following a myocardial infarction. National Insitute for Health Care Excellence, 2013.

10. Woodruffe S, Neubeck L, Clark R, et al. Australian Cardiovascular Health and Rehabilitation Association (ACRA) core components of cardiovascular disease secondary prevention and cardiac rehabilitation 2014. Hear Lung Circ 2015;24:430-41.

11. British Association for Cardiovascular Prevention and Rehabilitation. The BACPR standards and core components for cardiovascular disease prevention and rehabilitation 2012. 2nd edn. 2012.

12. Balady GJ, Williams MA, Ades PA, et al. Core components of cardiac rehabilitation/secondary prevention programs: 2007 update: a scientific statement from the American Heart Association Exercise, Cardiac Rehabilitation, and Prevention Committee, the Council on Clinical Cardiology; the Councils o. Circulation 2007;115:2675-82.

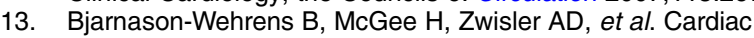
rehabilitation in Europe: results from the European Cardiac Rehabilitation Inventory Survey. Eur J Cardiovasc Prev Rehabil 2010;17:410-18.

14. Vromen T, Spee RF, Kraal JJ, et al. Exercise training programs in Dutch cardiac rehabilitation centres. Netherlands Hear $J$ 2013;21:138-43.

15. Brodie D, Bethell $\mathrm{H}$, Breen S. Cardiac rehabilitation in England: a detailed national survey. Eur J Cardiovasc Prev Rehabil 2006;13:122-8

16. Thompson DR, Bowman GS, Kitson AL, et al. Cardiac rehabilitation services in England and Wales: a national survey. Int $J$ Cardiol 1997;59:299-304.

17. McGee HM, Hevey D, Horgan JH. Cardiac rehabilitation service provision in Ireland: the Irish Association of Cardiac Rehabilitation survey. Ir J Med Sci 1998;170:159-62.

18. Briffa TG, Allan R, Maiorana A, et al. Physical activity for people with cardiovascular disease: recommendations of the National Heart Foundation of Australia. Med J Aust 2006;184:71-5.

19. Australian Cardiovascular Health and Rehabilitation Association, National Heart Foundation. Recommended Framework for Cardiac Rehabilitation '04. 2004. https://heartfoundation.org.au/images/ uploads/publications/Recommended-framework.pdf

20. Briffa TG, Kinsman L, Maiorana A, et al. An integrated and coordinated approach to preventing recurrent coronary heart disease events in Australia. Med J Aust 2009;190:683-6.

21. Australian Cardiovascular Health and Rehabilitation Association. CR Program Directories. 2015. http://www.acra.net.au/cr-services/ cr-directory/ (accessed 1 Sep 2015)

22. Hoffmann TC, Glasziou PP, Boutron I, et al. Better reporting of interventions: template for intervention description and replication (TIDieR) checklist and guide. BMJ 2014:348:g1687.

23. The American Association for Public Opinion Research. Standard definitions: final dispositions of case codes and outcome rates for surveys. 5th edn. Lenexa, Kansas, 2008.

24. Fletcher GF, Balady GJ, Amsterdam EA, et al. Exercise standards for testing and training: a statement for healthcare professionals from the American Heart Association. Circulation 2001;104:1694-740.

25. Fardy PS. Training techniques in cardiac rehabilitation. Champaign, IL: Human Kinetics, 1998.

26. Borg G. Borg's perceived exertion and pain scales. Champaign, IL: Human Kinetics, 1998.

27. Bradley JM, Wallace ES, McCoy PM, et al. A survey of exercise based cardiac rehabilitation services in Northern Ireland. Ulster Med $J$ 1997;66:100-6.
28. Breen S. Cardiac Rehabilitation Provision in England: a national survey (A Thesis submitted for the degree of Master of Philosophy). 2007.

29. Cortes-Bergoderi M, Lopez-Jimenez F, Herdy AH, et al. Availability and characteristics of cardiovascular rehabilitation programs in South America. J Cardiopulm Rehabil Prev 2013;33:33-41.

30. Vanhees L, McGee HM, Dugmore LD, et al. A representative study of cardiac rehabilitation activities in European Union Member States: the Carinex survey. J Cardiopulm Rehabil 2002;22:264-72.

31. Wolfe L, Dafoe W, Hendren-Roberge E, et al. Cardiovascular rehabilitation in Ontario (Canada). J Cardiopulm Rehabil 1990;10:130-40.

32. Kaminsky LA, Thur LA, Riggin K. Patient and program characteristics of early outpatient cardiac rehabilitation programs in the United States. J Cardiopulm Rehabil Prev 2013;33:168-72.

33. Zullo MD, Jackson LW, Whalen CC, et al. Evaluation of the recommended core components of cardiac rehabilitation practice: an opportunity for quality improvement. J Cardiopulm Rehabil Prev 2012;32:32-40.

34. Goble AJJ, Worcester MUC. Best practice guidelines for cardiac rehabilitation and secondary prevention. Human Services Victoria, 1999.

35. Scottish Intercollegiate Guidelines Network. Cardiac rehabilitation. (SIGN Guideline No 57). Scottish Intercollegiate Guidelines Network, 2002.

36. American Association of Cardiovascular and Pulmonary Rehabilitation. Guidelines for cardiac rehabilitation and secondary prevention programs. 5th edn. Champaign, IL: Human Kinetics, 2013.

37. Piepoli MF, Corrà U, Benzer W, et al. Secondary prevention through cardiac rehabilitation: from knowledge to implementation. A position paper from the Cardiac Rehabilitation Section of the European Association of Cardiovascular Prevention and Rehabilitation. Eur J Cardiovasc Prev Rehabil 2010;17:1-17.

38. Clark AM, Redfern J, Briffa T. Cardiac rehabilitation: fit to face the future? Heart 2014;100:355-6.

39. Clark RA, Conway A, Poulsen V, et al. Alternative models of cardiac rehabilitation: a systematic review. Eur J Prev Cardiol 2015;22:35-74

40. Balady GJ, Ades PA, Bittner VA, et al. Referral, enrollment, and delivery of cardiac rehabilitation/secondary prevention programs at clinical centers and beyond: a presidential advisory from the American Heart Association. Circulation 2011;124:2951-60.

41. Redfern J, Maiorana A, Neubeck L, et al. Achieving coordinated secondary prevention of coronary heart disease for all in need (SPAN). Int J Cardiol 2011;146:1-3.

42. Taylor RS, Dalal H, Jolly K, et al. Home-based versus centre-based cardiac rehabilitation. Cochrane Database Syst Rev 2015;(8): CD007130.

43. Griebsch I, Brown J, Beswick AD, et al. Is provision and funding of cardiac rehabilitation services sufficient for the achievement of The National Service Framework goals? Br J Cardiol 2004:11:307-9.

44. British Heart Foundation. National campaign for cardiac rehabilitation: cardiac rehabilitation...recovery or by-pass? London, 2007.

45. Smith J, Garton-Smith J, Briffa T, et al. The development of a new cardiac rehabilitation needs assessment tool (CRNAT) for individualised secondary prevention. Heart Lung Circ 2015;24:458-64.

46. Chow CK, Redfern J, Hillis GS, et al. Effect of lifestyle-focused text messaging on risk factor modification in patients with coronary heart disease. JAMA 2015;314:1255-63.

47. Varnfield M, Karunanithi M, Lee CK, et al. Smartphone-based home care model improved use of cardiac rehabilitation in postmyocardial infarction patients: results from a randomised controlled trial. Heart 2014;100:1770-9.

48. Taylor RS, Bethell HJ, Brodie DA. Clinical trials versus the real world: the example of cardiac rehabilitation. Br J Cardiol 2007;14:175-8.

49. Sandercock GRH, Cardoso F, Almodhy M, et al. Cardiorespiratory fitness changes in patients receiving comprehensive outpatient cardiac rehabilitation in the UK: a multicentre study. Heart 2013;99:785-90. 